\title{
Características fermentativas de silagens de cana-de-açúcar com erva-sal
}

\author{
Fermentation characteristics of sugarcane silages with saltbush
}

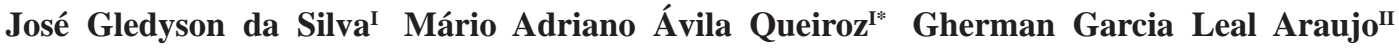 \\ Bruno Gonçalves da Silva ${ }^{\mathrm{I}}$ José Aparecido da Cunha ${ }^{\mathrm{III}}$ Paulo Henrique Mazza Rodrigues ${ }^{\mathrm{IV}}$
}

RESUMO

Objetivou-se com o presente estudo avaliar diferentes níveis $(0,20,40$ e 60\%) de inclusão de erva-sal na dinâmica fermentativa da silagem de cana-de-açúcar. Utilizou-se delineamento experimental inteiramente casualizado com quatro tratamentos e seis repetições. Após 90 dias, com a abertura dos silos, determinou-se os teores de carboidratos solúveis (CHOSol), etanol, ácidos orgânicos (lático, acético, propiônico, butírico), proteina bruta (PB), matéria mineral (MM), matéria seca (MS), fibra em detergente neutro livre de cinzas (FDNc), pH e poder tampão (PT); estimou-se a perda total de MS, perdas por efluente e gases, densidade e a recuperação da MS. Os níveis crescentes de erva-sal propiciaram diminuição das perdas totais de MS e por efluente, aumento de seu teor e recuperação desta. As silagens apresentaram $\mathrm{pH}$ adequado à conservação $(\leq 3,70) e$ concentração de minerais acrescidos. As concentrações de etanol foram influenciadas $(P<0,05)$ pelo incremento de erva-sal, em que se observou redução de $51,84 \%$, com $40 \%$ de erva-sal na silagem de cana. A adição de erva-sal reduz as perdas de MS e a produção de etanol e, melhora a qualidade fermentativa da silagem de canade-açúcar.

Palavras-chave: Atriplex nummularia, conservação de forragem, fermentação alcoolica.

\section{ABSTRACT}

The objective of this study was to evaluate different inclusion levels (0,20, 40 and 60\%) of old man saltbush in the fermentation dynamics of sugarcane silages. The experiment was carried out as a completely randomized design with four treatments and six replicates. After 90 days, with the opening of the silos, the levels of water soluble carbohydrates, ethanol, organic acids (lactic, acetic, propionic, butyric acid), crude protein (CP), mineral matter (MM), dry matter (DM), neutral detergent fiber ash free (NDFa), $p H$ and buffer capacity were determined; and, the losses by gas, effluent and total of dry mater, density and dry matter recovery were estimated. Increasing levels of saltbush propitiated reduction in losses: by effluent and total dry matter, it also increased the concentration and recovery. The silages showed $p H$ suitable for conservation $(\leq 3.70)$ and mineral concentration increased. The ethanol concentrations were influenced $(P<0.05)$ by the increase of saltbush, where reduction of $51.84 \%$ was observed, with $40 \%$ saltbush in sugarcane silage. The addition of saltbush reduces dry matter losses and ethanol production and, improves the quality of sugarcane silage.

Key words: Atriplex nummularia, forage conservation, alcoholic fermentation.

\section{INTRODUÇÃO}

A rota fermentativa da cana ensilada é caracterizada por produzir considerável concentração de etanol, que limita o consumo animal e ainda leva a uma significativa perda do valor nutritivo da forragem ao passar de sacarose para álcool, ocasionando elevadas perdas de MS; segundo SCHMIDT et al. (2007), em torno de 49\% em detrimento principalmente de CHO-Sol. Além do álcool produzido no processo de fermentação pelas leveduras, têm-se como produto deste, água, energia na forma de ATP, ácidos orgânicos e gás carbônico, sendo o último bastante significativo, isto porque, segundo PEDROSO et al.(2005) as perdas

\footnotetext{
'Universidade Federal do Vale do São Francisco (UNIVASF), Rodovia BR 407, km 12, lote 543, Projeto de Irrigação Nilo Coelho, S/N zona rural, 56310-770, Petrolina, PE, Brasil. E-mail: mario.queiroz@univasf.edu.br. *Autor para correspondência.

"Embrapa Semiárido, Petrolina, PE, Brasil.

IIIFaculdade de Zootecnia e Engenharia de Alimentos (FZEA), Universidade de São Paulo (USP), Pirassununga, SP, Brasil.

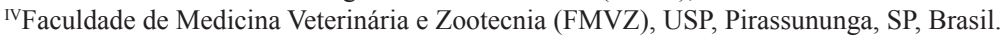


por gases, na ensilagem da cana-de-açúcar, são altamente correlacionadas ao teor de etanol $(90,3 \%)$ e à recuperação de MS (89,3\%). Dentre os ácidos orgânicos produzidos, destacam-se, para avaliação da qualidade do processo fermentativo, o ácido lático, acético, butírico e propiônico (TOMICH et al., 2003).

Por outro lado, a erva-sal (Atriplex nummularia), planta halófita, dentro do processo de conservação de forragens, pode constituir alternativa pela sua ação no aumento dos teores de MS e pelos elevados teores de sais, que possivelmente podem causar inibição do desenvolvimento de microrganismos indesejáveis, alterando o $\mathrm{pH}$ e a pressão osmótica da massa de forragem. SANTOS et al. (2012) verificaram melhorias nas características fermentativas da silagem do capim-elefante com a adição de erva-sal, a partir da obtenção de crescentes teores de ácido lático e reduzidas concentrações de ácido acético, propiônico e butírico.

Nesse contexto, pouco se sabe a respeito do uso potencial da erva-sal no processo de ensilagem por efeito associativo entre forrageiras, sendo escassos trabalhos que quantificam perdas fermentativas, produção de álcool, CHO-Sol e ácidos orgânicos em silagens de cana, em associação com plantas halófitas. Objetivou-se com esse estudo avaliar o efeito da inclusão de erva-sal em diferentes proporções, sobre a dinâmica fermentativa da silagem de cana-de-açúcar.

\section{MATERIAL E MÉTODOS}

O experimento foi conduzido na unidade da Embrapa Semiárido e no Laboratório de Bromatologia e Nutrição Animal da Universidade Federal do Vale do São Francisco, Campus Ciências Agrárias, ambos no município de Petrolina - PE. As silagens foram confeccionadas em silos adaptados, constituídos de baldes plásticos de $25 \mathrm{~L}$ com $2 \mathrm{~kg}$ de areia seca no fundo, protegida com tela fina de plástico e camada de tecido de algodão, para permitir a medida quantitativa do efluente produzido, e tampas com válvulas do tipo Bunsen, para escape dos gases e quantificação gravimétrica destes.

As forrageiras utilizadas, cana-de-açúcar cv. RB-92579 e erva-sal - Atriplex nummularia, foram colhidas manualmente em pleno estádio vegetativo, com idade aproximada de um ano (rebrota), trituradas separadamente em forrageira estacionária com tamanho de partícula variando de 2 a $3 \mathrm{~cm}$.

Oportunamente, no momento da ensilagem, amostraram-se os ingredientes para determinação de matéria seca, matéria mineral e proteína bruta (SILVA
\& QUEIROZ, 2002), obtendo-se 28,48\% (MS), $1,73 \%(\mathrm{MM})$ e $2,13 \%$ (PB) para a cana-de-açúcar e 31,00 (MS), 26,10 (MM) e 9,80 (PB) para a ervasal. Em seguida, procedeu-se à mistura experimental, obedecendo às devidas proporções $(0,20,40$ e $60 \%$ de erva-sal em substituição à cana-de-açúcar) e acomodação/compactação nos silos por pisoteio.

Posteriormente, os silos foram vedados e pesados para mensuração dos valores de densidade. Após o período de 90 dias, os silos foram pesados, em seguida abertos e a silagem amostrada. O conjunto vazio (silo, tampa, areia, tela e tecido de algodão) foi pesado para quantificação do efluente produzido e determinação da perda por gases e perda total de MS, de acordo com JOBIM et al. (2007).

A recuperação de MS foi obtida com base na diferença entre a massa seca inicialmente ensilada (neste caso $100 \%$ ) e a perda total ocorrida durante o processo de conservação, expressa em porcentagem. A densidade das silagens foi determinada em função da massa volumétrica da forragem ensilada, ou seja, relação entre massa verde compactada e o volume do silo, dada em $\mathrm{kg} \mathrm{MV} \mathrm{m}^{-3}$.

$\mathrm{Na}$ ocasião da retirada das silagens, foram coletadas amostras para obtenção de composição químico-bromatológica (SILVA \& QUEIROZ, 2002; MERTENS, 2002) e extrato aquoso (KUNG JR. et al., 1984), no qual foram determinados o $\mathrm{pH}$, PT e os teores de CHO-Sol (DUBOIS et al., 1956); ácido lático (SCHMIDT et al., 2007) em espectrofotômetro JENWAY-6405 UV/VIS ${ }^{\circledR}$; ácidos acético, propiônico e butírico em cromatógrafo líquido-gasoso CLG (Hewlett Packard $^{\circledR}$ 5890, series II) (PALMQUIST \& CONRAD, 1971) e o teor de etanol em analisador bioquímico YSI 2700 Select $^{\circledR}$.

$\mathrm{O}$ delineamento experimental utilizado foi o inteiramente casualizado, com quatro tratamentos $(0,20,40$ e $60 \%$ de erva-sal em substituição à cana-de-açúcar na confecção das silagens) e seis repetições. Os dados foram submetidos ao teste de normalidade e análise de variância por contrastes ortogonais e, quando significativo, à regressão polinomial, utilizando o procedimento GLM e REG, respectivamente (SAS, 2003).

\section{RESULTADOS E DISCUSSÃO}

$\mathrm{O}$ incremento de erva-sal nas silagens de cana promoveu menores $(\mathrm{P}<0,05)$ perdas totais da MS e por efluente (Tabela 1), constatando-se efeito linear decrescente em ambos, obtendo-se redução de 25,81 e $60,86 \%$, respectivamente, quando se observa os níveis 0 e $60 \%$ de erva-sal. Por outro lado, as 
perdas de MS ocasionadas por liberação de gases não foram afetadas $(\mathrm{P}>0,05)$ pela adição de erva-sal, assim como a densidade das silagens, observando-se médias de $14,00 \%$ MS e $569,83 \mathrm{~kg} \mathrm{MV} \mathrm{m}^{-3}$, na ordem de referência.

A inclusão de erva-sal beneficiou $(\mathrm{P}<0,05)$ ainda a recuperação da $\mathrm{MS}$, verificando-se efeito linear crescente, proporcionando recuperação de $87,35 \%$ com $60 \%$ de erva-sal contra $82,96 \%$ do tratamento controle ( $0 \%$ de erva-sal). A cada inclusão de $20 \%$ de Atriplex, houve incremento de 2,8\% na MS das silagens $(\hat{y}=23,47+0,14 x ; R 2=0,73)$. O menor $(24,43 \%)$ e maior $(30,97 \%)$ valor de MS observado nos níveis 0 e $40 \%$ de erva-sal, respectivamente, encontram-se dentro da faixa $(>25 \%)$ recomendada por McDONALD et al. (1991).

Valores percentuais de redução de perda total da MS deste trabalho $(25,81 \%)$ corroboram os encontrados por FREITAS et al. (2006) (28,30\%) em silagem de cana-de-açúcar aditivada com Lactobacillus plantarum $\left(1,0 \times 10^{6} \mathrm{ufc}^{-1}\right.$ de matéria natural) e enriquecida com resíduo da colheita de soja (10\% de matéria natural).

Resultados semelhantes, dentro da faixa observada para recuperação da MS, foram obtidos por SANTOS et al. (2008), fazendo uso de óxido de cálcio a $1,5 \%$ em silagens de cana $(84,11 \%)$. Com esse tratamento, a melhor resposta exibida foi da variável perda por efluente $\left(19,68 \mathrm{~kg} \mathrm{t}^{-1} \mathrm{MV}\right)$, muito embora seja inferior ao verificado neste estudo $\left(5,48 \mathrm{~kg} \mathrm{t}^{-1}\right.$ MV) com inclusão de $60 \%$ de erva-sal.

Possivelmente, os menores valores de perdas de MS total e maiores de recuperação encontrados neste ensaio estejam relacionados à diminuição das altas concentrações de açúcares solúveis da cana (SANTOS et al., 2008), em função da diluição promovida pela erva-sal, assim como da menor presença de microrganismos indesejáveis no momento da ensilagem.
O teor de minerais é outro fator a ser considerado no tocante à inibição do crescimento de microrganismos. Observou-se aumento $(\mathrm{P}<0,05)$ de $155,90 \%$ (modelo linear crescente), ponderando as inclusões 0 e $60 \%$ de erva-sal. A alta concentração do íon sódio, dominante na erva-sal (SOUZA et al., 2011), concorre para uma alta pressão osmótica, o protoplasma das células dos microrganismos se desidrata, havendo contração da membrana plasmática (plasmólise). Em virtude disso, o desenvolvimento destes é obstado (REZENDE et al., 2011).

$\mathrm{O}$ alto teor de minerais encontrado nas silagens de cana-de-açúcar com erva sal melhorou o perfil fermentativo com a redução do teores de álcool, porém, pode ser um limitante de consumo. Segundo BRITO et al., (2007), estudando níveis crescentes de feno de erva-sal como único volumoso na dieta de cordeiros em crescimento, o consumo de matéria seca foi menor $\left(1,52 \mathrm{~kg} \mathrm{MS}\right.$ animal $\left.{ }^{-1} \mathrm{dia}^{-1}\right)$ no maior nível de inclusão de feno de erva-sal, de $66 \%$, indicando que seu elevado teor de sódio pode limitar o consumo pelos animais.

Os teores de CHO-Sol sofreram redução $(\mathrm{P}<0,05)$ de $79,91 \%$ com adição $60 \%$ de erva-sal em relação ao tratamento controle, apresentando efeito linear decrescente (Tabela 2). Acredita-se que o efeito de dispersão dos CHO-Sol em função da diluição promovida pela erva-sal possa explicar melhor tal comportamento. Apesar disso, não se observa variação $(\mathrm{P}>0,05)$ no teor de parede celular, expressa em FDNc, com média 64,65\% da MS.

A inclusão de erva-sal afetou $(\mathrm{P}<0,05)$ também a concentração de etanol (Tabela 2). Observou-se diminuição de $51,84 \%$, considerandose os intervalos 0 e $40 \%$ de incremento. PEDROSO et al. (2011), trabalhando com aditivos químicos associados, e CAVALI et al. (2010), com inoculante bacteriano e inclusão de capim-elefante na ensilagem de cana, observaram resultados semelhantes, obtendo

Tabela 1 - Perdas fermentativas, recuperação de matéria seca e densidade de silagens de cana-de-açúcar com diferentes proporções de erva-sal.

\begin{tabular}{|c|c|c|c|c|c|c|c|}
\hline \multirow{2}{*}{ Variáveis } & - & veis de e & al (\%)- & -------- & \multirow{2}{*}{$\mathrm{EP}^{(1)}$} & \multirow{2}{*}{$\mathrm{R}^{2}$} & \multirow{2}{*}{$\mathrm{ER}^{(2)}$} \\
\hline & 0 & 20 & 40 & 60 & & & \\
\hline Matéria seca ${ }^{(3)}$ & 24,43 & 28,09 & 30,97 & 30,00 & 0,660 & 0,73 & $\hat{\mathrm{y}}=23,47+0,14 \mathrm{x}^{*}$ \\
\hline Perdas por efluente ${ }^{(4)}$ & 14,00 & 14,00 & 6,98 & 5,48 & 1,646 & 0,78 & $\hat{\mathrm{y}}=15,707-0,178 \mathrm{x}^{*}$ \\
\hline Perdas por gases ${ }^{(3)}$ & 15,78 & 12,70 & 14,45 & 13,07 & 0,683 & - & $\hat{\mathrm{y}}=14,00$ \\
\hline Perda total de $\mathrm{MS}^{(5)}$ & 17,05 & 13,48 & 14,57 & 12,65 & 0,742 & 0,67 & $\hat{y}=16,252-0,0605 x^{*}$ \\
\hline Recuperação da MS ${ }^{(5)}$ & 82,96 & 86,52 & 85,44 & 87,35 & 0,745 & 0,66 & $\hat{y}=0,0554 x+83,987 *$ \\
\hline Densidade $^{(6)}$ & 572,00 & 566,00 & 573,33 & 568,00 & 4,201 & - & $\hat{y}=569,83$ \\
\hline
\end{tabular}

* Significativo $\mathrm{P}<0,05 .{ }^{(1)}$ Erro-padrão da média. ${ }^{(2)}$ Equação de regressão, teste de polinômio ortogonal, resposta linear, quadrática ou cúbica. (3) $\%$ da MS. ${ }^{(4)} \mathrm{kg} \mathrm{t}^{-1} \mathrm{MV} .{ }^{(5)} \%$. ${ }^{(6)} \mathrm{kg} \mathrm{MV} \mathrm{m}^{-3}$. 
53,74 e 67,37\% de redução do teor de etanol, respectivamente.

Neste trabalho, a partir do terceiro nível de erva-sal $(40 \%)$, o comportamento da relação "inclusão de erva-sal" e "produção de etanol" passou a ser crescente, verificando-se efeito quadrático, tendo-se 51,19\% como melhor nível de inclusão de Atriplex para a menor produção de álcool $(13,63 \%$ da MS).

Com relação aos ácidos orgânicos (Tabela 2), não houve efeito $(\mathrm{P}>0,05)$ com a participação da erva-sal nas silagens sobre a produção do lactato (média de 1,15\% da MS). Já o ácido acético que, em detrimento do lactato, tem se mostrado mais eficaz em reduzir a população de leveduras (RANJIT \& KUNG JR., 2000) e consequentemente a concentração de etanol, foi influenciado $(\mathrm{P}<0,05)$ com a adição de erva-sal, registrando-se valores consideráveis $(2,43 \%$ da MS com $100 \%$ de cana), acima do proposto por SILVEIRA (1987) como aceitável $(0,8 \%$ da MS).

Essa maior concentração de acetato pode ter sido resultado do momento da compactação da massa forrageira, quando a presença de oxigênio na silagem pode ter levado ao desenvolvimento prolongado de microrganismos anaeróbios facultativos (MUCK, 1988) e ao aumento da concentração do ácido nas silagens.

Quanto à variável ácido acético, verificouse redução $(\mathrm{P}<0,05)$ de $35,80 \%$, considerando-se as adições 0 e $60 \%$ de erva-sal. A saber, o acido acético possui princípio antifúngico sobre a fermentação (KLEINSCHMIT et al., 2005). Acredita-se que sua redução nos níveis 40 e $60 \%$ de erva sal possa ter propiciado retorno da atividade metabólica das leveduras e consequente aumento da produção de etanol.

Para avaliar a qualidade do processo fermentativo, analisou-se também o $\mathrm{pH}$ das silagens. Observaram-se diferenças $(\mathrm{P}<0,05)$ com o incremento de erva-sal, ocorrendo acréscimo linear. Os valores de $\mathrm{pH}$ mínimo $(3,47)$ e máximo $(3,70)$ para 0 e $40 \%$ de erva-sal, respectivamente, encontram-se dentro de uma faixa recomendada $(3,6$ e 4,2) por TOMICH et al. (2004), a qual afirma ser aceitável para garantir boa preservação da massa ensilada, restringindo a ação de enzimas proteolíticas da planta e de enterobactérias e clostrídios.

Nesta faixa, também PEDROSO et al. (2005) e EVANGELISTA et al. (2009) observaram valores de $\mathrm{pH}$ de silagens de cana-de-açúcar próximos a 3,8. Acredita-se que a variação do $\mathrm{pH}$ neste trabalho, possivelmente, esteja relacionado à menor atividade de microrganismos fermentadores, que sintetizam lactato e AGVs, que atuam na diminuição dos valores de $\mathrm{pH}$ em virtude da redução gradativa $(\mathrm{P}<0,05)$ da concentração de seu substrato, os CHO-Sol, ao passo que se substituiu percentualmente a cana pela ervasal; tais açucares estão presentes em altos teores na cana-de-açúcar. O efeito tampão não sofreu variação $(\mathrm{P}>0,05)$.

Com relação aos demais ácidos orgânicos avaliados (propiônico e butírico), apenas o propionato sofreu $(\mathrm{P}<0,05)$ alteração em sua concentração (efeito linear decrescente), com faixa de $0,08-0,03 \%$ da MS, correspondente à adição 0 - $60 \%$ de erva-sal.

Tabela 2 - Valores de pH, poder tampão (PT), carboidratos solúveis (CHO-Sol), Etanol, proteína bruta (PB), matéria mineral (MM), fibra em detergente neutro livre de cinzas (FDNc) e ácidos orgânicos (acetato, propionato, butirato e lactato) de silagens de cana-de-açúcar com diferentes proporções de erva-sal.

\begin{tabular}{|c|c|c|c|c|c|c|c|}
\hline \multirow{2}{*}{ Variáveis } & \multicolumn{4}{|c|}{-Níveis de erva-sal (\%)---------------- } & \multirow{2}{*}{$\mathrm{EP}^{(1)}$} & \multirow{2}{*}{$\mathrm{R}^{2}$} & \multirow{2}{*}{$\mathrm{ER}^{(2)}$} \\
\hline & 0 & 20 & 40 & 60 & & & \\
\hline $\mathrm{pH}$ & 3,47 & 3,48 & 3,70 & 3,69 & 0,013 & 0,85 & $\hat{y}=3,45171+0,00393 x^{*}$ \\
\hline $\mathrm{PT}^{(3)}$ & 19,37 & 23,23 & 20,89 & 24,43 & 0,592 & - & $\hat{\mathrm{y}}=21,98$ \\
\hline CHO-Sol ${ }^{(4)}$ & 20,11 & 5,42 & 5,05 & 4,04 & 1,327 & 0,64 & $\hat{y}=14,67268-0,22833 x^{*}$ \\
\hline Etanol $^{(4)}$ & 35,69 & 22,89 & 13,62 & 14,47 & 0,586 & 0,97 & $\hat{\mathrm{y}}=0,0085-0,8702 \mathrm{x}+35902 \mathrm{x}^{2} *$ \\
\hline Proteína bruta ${ }^{(4)}$ & 3,32 & 4,11 & 4,78 & 4,68 & 0,151 & 0,82 & $\hat{\mathrm{y}}=3,04+0,03 \mathrm{x}^{*}$ \\
\hline Matéria mineral ${ }^{(4)}$ & 4,58 & 8,24 & 10,70 & 11,72 & 0,714 & 0,93 & $\hat{\mathrm{y}}=2,84+0,17 \mathrm{x}^{*}$ \\
\hline $\mathrm{FDNc}^{(4)}$ & 63,94 & 65,58 & 63,49 & 65,60 & 0,535 & - & $\hat{y}=64,65$ \\
\hline Ácido acético ${ }^{(4)}$ & 2,49 & 1,90 & 1,51 & 1,57 & 0,066 & 0,81 & $\hat{y}=2,30049-0,01638 x^{*}$ \\
\hline Ácido propiônico ${ }^{(4)}$ & 0,08 & 0,05 & 0,04 & 0,03 & 0,003 & 0,77 & $\hat{y}=0,07341-0,00064634 x^{*}$ \\
\hline Ácido butírico ${ }^{(4)}$ & 0,012 & 0,001 & 0,159 & 0,000 & 0,040 & - & $\hat{\mathrm{y}}=0,04$ \\
\hline Ácido lático ${ }^{(4)}$ & 1,13 & 1,26 & 0,75 & 1,44 & 0,119 & - & $\hat{\mathrm{y}}=1,15$ \\
\hline
\end{tabular}

* Significativo $\mathrm{P}<0,05 .{ }^{(1)}$ Erro-padrão da média. ${ }^{(2)}$ Equação de regressão, teste de polinômio ortogonal, resposta linear, quadrática ou cúbica.

${ }^{(3)} \mathrm{Meq}$ de $\mathrm{HCl} 100 \mathrm{~g}^{-1} \mathrm{MS} .{ }^{(4)} \%$ da MS. 
Assim como o $\mathrm{pH}$, pode-se inferir que a variação significativa do acetato e propionato neste estudo provavelmente deva-se à diminuição gradual da concentração do substrato (CHO-Sol) dos microrganismos, enterobactérias e clostrídios que participam no processo fermentativo com a produção dos ácidos orgânicos.

O ácido butírico, que por sua vez não foi significativo aos níveis testados, apresentou valores muito próximos a zero, com média de $0,04 \%$ da MS. Maiores teores de butirato refletem a influência da atividade clostridiana sobre a massa ensilada, com a degradação de proteínas, glicose e ácido lático (McDONALD et al., 1991).

O teor de $\mathrm{PB}$ nas silagens foi afetado $(\mathrm{P}<0,05)$ pela adição de erva-sal, inferindo-se comportamento linear crescente, com incremento de 40,96\%, ajustandose aos níveis 0 e $60 \%$ de erva-sal. SANTOS et al. (2012) obtiveram, percentualmente, acréscimos semelhantes com silagens de capim-elefante associada a níveis crescentes de erva-sal, $41,86 \% \mathrm{~PB}$, no nível $60 \%$, em relação a $0 \%$ de erva-sal.

\section{CONCLUSÃO}

A inclusão de erva-sal em níveis crescentes em silagens de cana-de-açúcar reduz as perdas totais de matéria seca, melhora o perfil fermentativo, porém aumenta os teores de matéria mineral.

\section{REFERÊNCIAS}

BRITO, EA. et al. Níveis de inclusão de feno de atriplex (Atriplex nummularia Lind.) sobre o desempenho de cordeiros em crescimento. In: SIMPÓSIO INTERNACIONAL SOBRE OVINOS E CAPRINOS DE CORTE, 3., 2007, João Pessoa, PB. Anais... João Pessoa: SIMCORTE, 2007. 1 CD-ROM.

CAVALI, J. et al. Mixed sugarcane and elephant grass silages with or without bacterial inoculant. Revista Brasileira de Zootecnia, v.39, n.3, p.462-470, 2010. Disponível em: <http://www.scielo. br/pdf/rbz/v39n3/a03v39n3.pdf>. Acesso em: 21 dez. 2012. doi: 10.1590/S1516-3598.2010.000300003.

DUBOIS, M. et al. Colorimetric method for determination of sugars and related substances. Analytical Chemistry, v.28, p.350, 1956.

EVANGELISTA, A.R. et al. Alterações bromatológicas e fermentativas durante o armazenamento de silagens de cana-deaçúcar com e sem milho desintegrado com palha e sabugo. Revista Brasileira de Zootecnia, v.38, n.1, p.20-26, 2009. Disponível em: $<$ http://www.scielo.br/pdf/rbz/v38n1/a03v38n1.pdf >. Acesso em: 21 dez. 2012. doi: 10.1590/S1516-3598.2009.000100003.

FREITAS, A.W.P.F. et al. Avaliação da qualidade nutricional da silagem de cana-de-açúcar com aditivos microbianos e enriquecida com resíduos da colheita da soja. Revista Brasileira de Zootecnia, v.35, n.1, p.38-47, 2006. Disponível em: <http://www. scielo.br/pdf/rbz/v35n1/28340.pdf>. Acesso em: 21 dez. 2012. doi: 10.1590/S1516-3598.2006.000100005.

JOBIM, C.C. et al. Avanços metodológicos na avaliação da qualidade da forragem conservada. Revista Brasileira de Zootecnia, v.36, p.101-119, 2007. Disponível em: $<$ http://www. scielo.br/pdf/rbz/v36s0/13.pdf $>$. Acesso em: 22 dez. 2012. doi: 10.1590/S1516-35982007001000013.

KLEINSCHMIT, D.H. et al. The effects of various antifungal additives on the fermentation and aerobic stability of corn silage. Journal of Dairy Science, v.88, p.2130-2139, 2005. Disponível em: <http://www.sciencedirect.com/science/article/pii/ S0022030205728897>. Acesso em: 22 dez. 2012. doi: 10.3168/ jds.S0022-0302(05)72889-7.

KUNG JR., L. et al. Added ammonia or microbial inocula for fermentation and nitrogenous compounds of alfalfa ensiled at various percents of dry matter. Journal of Dairy Science, v.67, p.299-306, 1984. Disponível em: <http://www.sciencedirect.com/ science/article/pii/S0022030284813028>. Acesso em: $21 \mathrm{dez}$. 2012. doi: 10.3168/jds.S0022-0302(84)81302-8.

McDONALD, P. et al. The biochemistry of silage. 2.ed. Merlow: Chalcombe Publications, 1991. 340p.

MERTENS, D.R. Gravimetric determination of amylase-treated neutral detergent fiber in feeds with refluxing in beaker or crucibles: collaborative study. Journal of AOAC International, v.85, p.1217-1240, 2002.

MUCK, R.E. Factors influencing silage quality and their implications for management. Journal of Dairy Science, v.71, p.2992-3002, 1988. Disponível em: <http://www.sciencedirect. com/science/article/pii/S0022030288798975>. Acesso em: 21 dez. 2012. doi: 10.3168/jds.S0022-0302(88)79897-5.

PALMQUIST, D.; CONRAD, H. Origin of plasma fatty acids in lactating cows fed high fat diets. Journal of Dairy Science, v.54, p.1025-1033, 1971. Disponível em: <http://www.sciencedirect. com/science/article/pii/S0022030271859660>. Acesso em: 21 dez. 2012. doi: 10.3168/jds.S0022-0302(71)85966-0.

PEDROSO, A.F. et al. Aditivos químicos e inoculante bacteriano na ensilagem de cana-de-açúcar: efeitos sobre a fermentação das silagens e o desempenho de garrotes. Revista Brasileira de Zootecnia, v.40, n.6, p.1181-1187, 2011. Disponível em: <http:// www.scielo.br/pdf/rbz/v40n6/04.pdf>. Acesso em: 21 dez. 2012. doi: 10.1590/S1516-3598.2011.000600004.

PEDROSO, A.F. et al. Fermentation and epiphytic microflora dynamics in sugar cane silage. Scientia Agricola, v.62, n.5, p.427-432, 2005. Disponível em: <http://www.scielo.br/pdf/ sa/v62n5/25980.pdf $>$. Acesso em: 21 dez. 2012. doi: 10.1590/ S0103-9016.2005.000500003.

RANJT, N.K.; KUNG JR., L. The effect of Lactobacillus buchneri, Lactobacillus plantarum, or a chemical preservative on the fermentation and aerobic stability of corn silage. Journal of Dairy Science, v.83, p.526-535, 2000. Disponível em: <http://www.sciencedirect.com/ science/article/pii/S0022030200749125>. Acesso em: $21 \mathrm{dez} .2012$. doi: 10.3168/jds.S0022-0302(00)74912-5.

REZENDE, A.V. et al. Perdas fermentativas e estabilidade aeróbia de silagens de cana-de-açúcar tratadas com cal virgem e cloreto de sódio. Revista Brasileira de Zootecnia, v.40, n.4, 
p.739-746, 2011. Disponível em: <http://www.scielo.br/pdf/rbz/ v40n4/06.pdf>. Acesso em: 26 jul. 2013. doi: 10.1590/S151635982011000400006 .

SANTOS, M. C. et al. Influência da utilização de aditivos químicos no perfil da fermentação, no valor nutritivo e nas perdas de silagens de cana-de-açúcar. Revista Brasileira de Zootecnia, v.37, n.9, p.1555-1563, 2008. Disponível em: <http://www.scielo. br/pdf/rbz/v37n9/a06v37n9.pdf $>$. Acesso em: 21 dez. 2012. doi: 10.1590/S1516-3598.2008.000900006.

SANTOS, O.O. et al. Fermentation characteristics and nutritional value of elephant grass ensiled with old man saltbush. Revista Brasileira de Zootecnia, v.41, n.6, p.1401-1406, 2012. Disponível em: $<\mathrm{http}: / /$ www.scielo.br/pdf/rbz/v41n6/12.pdf> . Acesso em: 21 dez. 2012. doi: 10.1590/S1516-3598.2012.000600012.

SAS INSTITUTE. SAS/STAT: guide for personal computer; version 9.1. Cary, 2003. 235p.

SCHMIDT, P. et al. Aditivos químicos e biológicos na ensilagem de cana-de-açúcar. 1. Composição química das silagens, ingestão, digestibilidade e comportamento ingestivo. Revista Brasileira de Zootecnia, v.36, p.1666-1675, 2007. Disponível em: <http:// www.scielo.br/pdf/rbz/v36n5s0/a27v3650.pdf>. Acesso em: 21 dez. 2012. doi: 10.1590/S1516-3598.2007.000700027.
SILVA, D.J.; QUEIROZ, A.C. Análise de alimentos: métodos químicos e biológicos. 3.ed. Viçosa: UFV, 2002. 235p.

SILVEIRA, A.C. Produção e utilização de silagens. In: SEMANA DE ZOOTECNIA, 12., 1987, Pirassununga, SP. Anais... Pirassununga: Fundação Cargill, 1987. p.119-134.

SOUZA, E.R. et al. Fitoextração de sais pela Atriplex nummularia lindl. sob estresse hídrico em solo salino sódico. Revista Brasileira de Engenharia Agrícola e Ambiental, v.15, n.5, p.477-483, 2011. Disponível em: <http://www.scielo.br/pdf/rbeaa/ v15n5/v15n5a07.pdf>. Acesso em: 27 jul. 2013. doi: 10.1590/ S1415-43662011000500007.

TOMICH, T.R. et al. Características químicas para avaliação do processo fermentativo de silagens: uma proposta para qualificação da fermentação. Corumbá: Embrapa Pantanal, 2003. 20 p. (Série Documentos da EMBRAPA).

TOMICH, T.R. et al. Características químicas e digestibilidade in vitro de silagens de girassol. Revista Brasileira de Zootecnia, v.33, n.6, p.1672-1682, 2004. Disponível em: <http://www.scielo. br/pdf/rbz/v33n6s1/a05336s1.pdf >. Acesso em: 21 dez. 2012. doi: 10.1590/S1516-3598.2004.000700005. 